\title{
Molecular alterations in columnar cell lesions of the breast
}

\author{
David J Dabbs, Gloria Carter, Mary Fudge, Yan Peng, Pat Swalsky and Sidney Finkelstein \\ Department of Pathology, University of Pittsburgh, Pittsburgh, PA, USA
}

\begin{abstract}
Columnar cell lesions of the breast include a morphologic spectrum of simple columnar cell change, columnar cell hyperplasia, columnar cell hyperplasia with atypia and ductal carcinoma in situ of micropapillary/cribriform type. Invasive carcinomas of low grade are often seen in association with this spectrum. The biologic significance of these lesions that are commonly found on breast biopsies is unknown. Three cases of formalinfixed, paraffin-embedded breast tissues, each displaying the entire spectrum of columnar cell lesions through ductal carcinoma in situ and including foci of invasive carcinoma were microdissected at multiple sites to evaluate neoplasia progression. Minute tissue targets were microdissected (4-8/case) from unstained $4-\mu \mathrm{m}$ thick recut paraffin sections and included non-neoplastic breast and sites of columnar cell change, hyperplasia, atypia, ductal carcinoma in situ and invasive carcinoma. Allelic imbalance for a broad panel of microsatellite markers in proximity to known tumor suppressor genes was quantitated using automated polymerase chain reaction/gel electrophoresis. Genomic loci evaluated 1p, 3p, 5q, 9p, 9q, 10q, 17p, 17q, 19q, 22q. The presence, topographic relationship and time course of mutational damage was correlated with columnar morphologic features. Detailed allelic imbalance information was obtained from each microdissection tissue target producing a detailed fingerprint of mutational damage in each case. Allelic damage was targeted predominately at $9 q, 10 q, 17 p$ and $17 q$. Simple columnar cell change was without mutational changes and only present in one case of columnar cell hyperplasia. The remainder of the cases all show progressive accumulation of allelic damage in columnar cell changes with atypia, ductal carcinoma in situ and invasive carcinoma. The fractional mutation percentage increased progressively from columnar cell hyperplasia through invasive carcinoma. Low level of allelic imbalance was demonstrable in columnar cell lesions by the microdissection approach. A gradient of progressive mutational change could be delineated in each case manifesting allelic loss damage. Allelic loss damage appeared to preferentially target loci at $9 q, 10 q, 17 p$ and $17 q$. The findings are consonant with the hypothesis that a select group of atypical columnar cell lesions are morphologic precursors to invasive carcinoma. Integrated molecular pathology analysis used here can help define the significance of columnar cell lesions and its role in breast cancer tumorigenesis on an individual patient basis.

Modern Pathology (2006) 19, 344-349. doi:10.1038/modpathol.3800538; published online 6 January 2006
\end{abstract}

Keywords: breast; columnar cells; molecular alterations

Breast terminal duct epithelium which assumes a columnar morphologic appearance has been recognized for decades, and has been referred to by a variety of names, including abnormal involution, cystic lobules, atypical cystic lobules, atypical lobules, hyperplastic unfolded lobules, hyperplastic lobules, columnar alteration with prominent apical snouts and secretions and enlarged lobular units with columnar alteration. ${ }^{1-16}$ Illustrations of the columnar alterations in published papers and textbooks reveal a transformation of the terminal duct-

Correspondence: Dr DJ Dabbs, MD, Department of Pathology, Magee-Women's Hospital, 300 Halket Street, Pittsburgh, PA 15213, USA.

E-mail: ddabbs@mail.magee.edu

Received 9 August 2005; revised 15 November 2005; accepted 16 November 2005; published online 6 January 2006 lobular unit from a low cuboidal epithelium to a tall columnar epithelium that is often cystically dilated to some degree. This altered cell type, or columnar cell change may be associated with a normal lobular size, a lobule which is enlarged or a lobule which is enlarged and dilated. Invariably, low magnification reveals a distinct eye-catching blue color to the columnar arrangement as a manifestation of the increased numbers of cells per lobular unit area.

A spectrum of epithelial pathologies composed of columnar cell lesions frequently coexist. In addition to the simple columnar cell change of the lobule, there may be columnar cell hyperplasia with or without atypia, and atypia may also manifest as 'flat atypia' which is cytological high-grade atypia without abundant epithelial proliferation. ${ }^{17}$ Flat atypia likely represents a morphologic form of atypical duct epithelial hyperplasia. One-third of follow-up 
excisions of flat atypia show more serious pathology, an incidence analogous to excisional follow-up of atypical duct epithelial hyperplasia. ${ }^{18}$

Epithelial thickening, or piling up in the pattern of hyperplasia may ensue. Atypia of cytologic or architectural type (club-shaped micropapillae, Roman arches) may accompany hyperplastic epithelium. The duct carcinoma in situ (DCIS) most commonly seen in association is the low grade, micropapillary/cribriform type.

The spectrum of changes seen within columnar cell lesions implies an association of progression to atypia/carcinoma. To date there are no molecular studies that support such a hypothesis. The goal of this study is to examine the above-mentioned morphologic spectrum in order to determine if there is a molecular spectrum of abnormalities that would support a molecular progression from columnar cell change through DCIS and invasive carcinoma.

We chose to employ loss of heterozygosity $(\mathrm{LOH})$ studies to examine for microsatellite alterations in each of the morphologic entities of columnar change, columnar hyperplasia, columnar atypia, ductal carcinoma in situ and invasive carcinoma. Evidence of a molecular precursor status would demonstrate $\mathrm{LOH}$ (an informative sample) and that specific LOH would necessarily be present in subsequent recognized putative morphologic precursors to carcinoma as well as in the carcinoma.

\section{Materials and methods}

Ten cases of formalin-fixed, paraffin-embedded breast tissues that showed columnar alterations were used. Seven of the cases displayed the entire spectrum of columnar cell change through DCIS, and included foci of invasive carcinoma (Figures 1-6).

All cases were microdissected with a dissecting microscope at multiple sites to evaluate for neoplas-

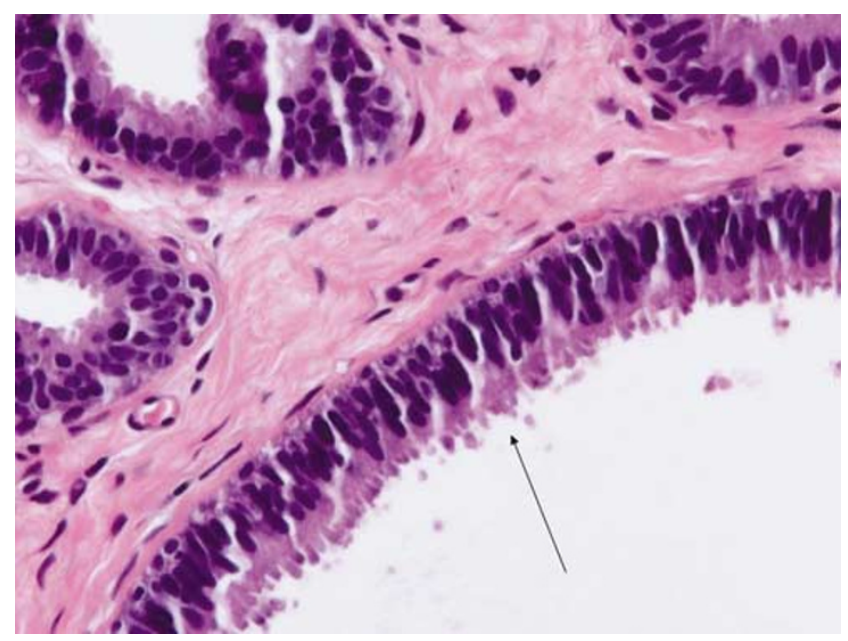

Figure 1 Columnar cell change with apical snouts for molecular study (arrow).

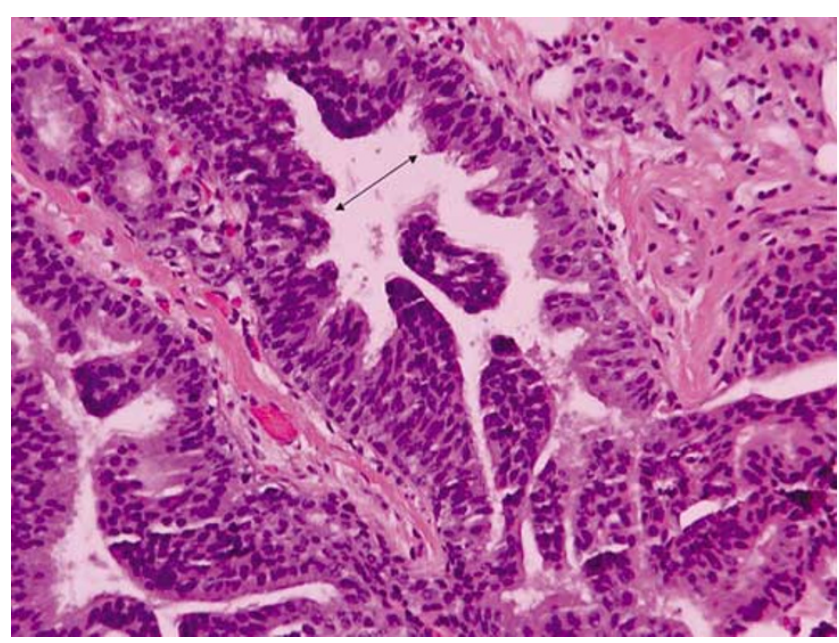

Figure 2 Columnar cell hyperplasia with epithelial stratification and luminal bridging, area chosen for molecular study (arrow).

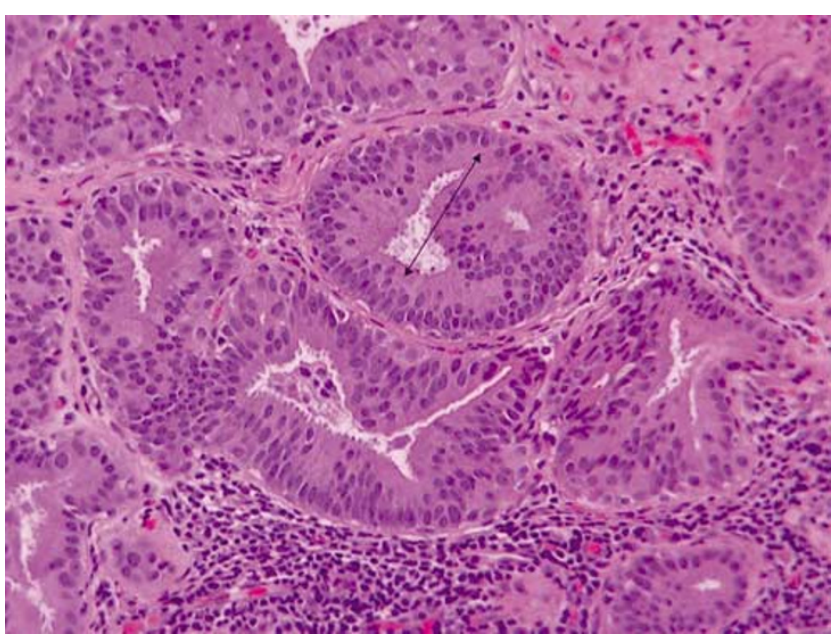

Figure 3 Atypical columnar cell change with marked cytological atypia. Arrow denotes site of molecular study.

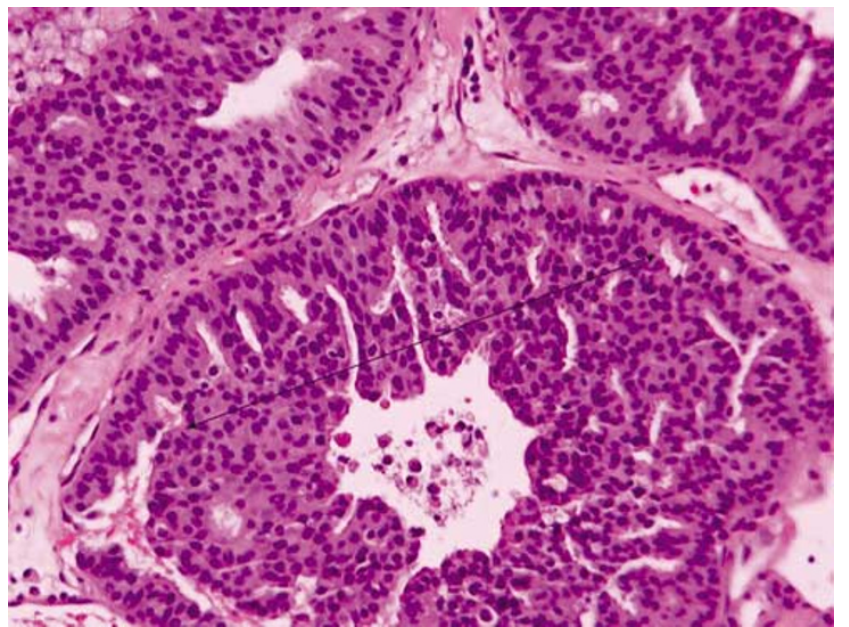

Figure 4 DCIS cribriform type, area of molecular study. 
tic progression. Minute tissue targets were microdissected (4-8/case) from unstained $4-\mu \mathrm{m}$ thick recut paraffin sections and included non-neoplastic breast and sites of columnar cell change, columnar cell hyperplasia, manifested by $>2$ cell layers of columnar cells without cytoarchitectural atypia, atypical columnar cell hyperplasia, manifested by $>2$ cells thick with cytologic or architectural atypia, DCIS (micropapillary/cribriform types) and invasive carcinoma. There were no cases of pure 'flat atypia.'

Allelic imbalance for a broad panel of microsatellite markers in proximity to known tumor

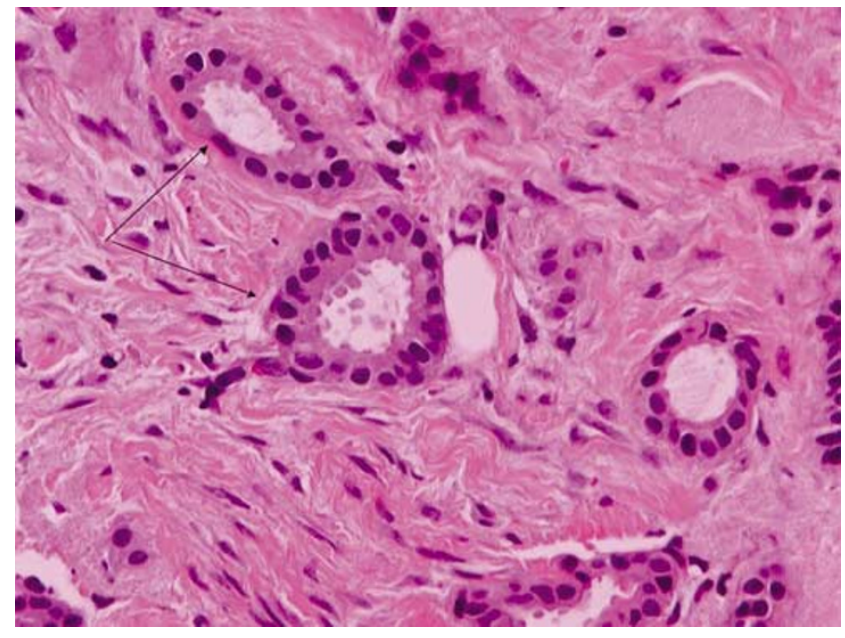

Figure 5 Infiltrating carcinoma, tubular type. Arrows denote zones for molecular study. suppressor genes was quantitated using automated PCR/gel electrophoresis. Genomic loci evaluated 1p, 3p, 5q, 9p, 9q, 10q, 17p, 17q, 19q, 22q. A total of 20 specific microsatellite regions from these 10 chromosomal sites were evaluated (Table 1). The percentage of material showing mutation was always greater than $50 \%$. Of 43 sites, 1040 total tests were performed with 277 noninformative tests.

The presence, topographic relationship and time course of mutational damage was correlated with columnar morphologic features.

Tumor suppressor gene loss was based on determination of LOH for informative loci situated within or adjacent to specific genes of interest. DNA polymorphisms were in the form of polymorphic microsatellites with polymerase chain reaction (PCR) primers based on cytogenetic location and GenBank references as follows:

1p36:D1S407[L18040], 1p34:MYCL[M19720], 3p26:D3S1539[L16393], 3p25:D3S2303[L17972],

Table 1 Microsatellite loci examined in microdissected areas

\begin{tabular}{lccc}
\hline 1p36.21 & D1S1193 & 10q23.31 & D10S520 \\
1p36.21 & D1S407 & 10q23.31 & D10S1173 \\
1p34.1 & MYCL & 10q24.3 & MXI1 \\
3p26.3 & D3S1539 & $17 \mathrm{p} 13.1$ & D17S974 \\
3p25.3 & D32303 & $17 \mathrm{p} 13.1$ & D17S1289 \\
$5 \mathrm{q} 23.3$ & D5S592 & $17 \mathrm{q} 12$ & D17S907 \\
$5 \mathrm{q} 23.3$ & D5S615 & $19 \mathrm{q} 12$ & D19S449 \\
9p23 & D9S254 & $19 \mathrm{q} 12$ & D19S500 \\
9p21.3 & D9S251 & $22 \mathrm{q} 22$ & D22S532 \\
$9 \mathrm{q} 22.1$ & D9S252 & $22 \mathrm{q} 22$ & D22S444 \\
\hline
\end{tabular}

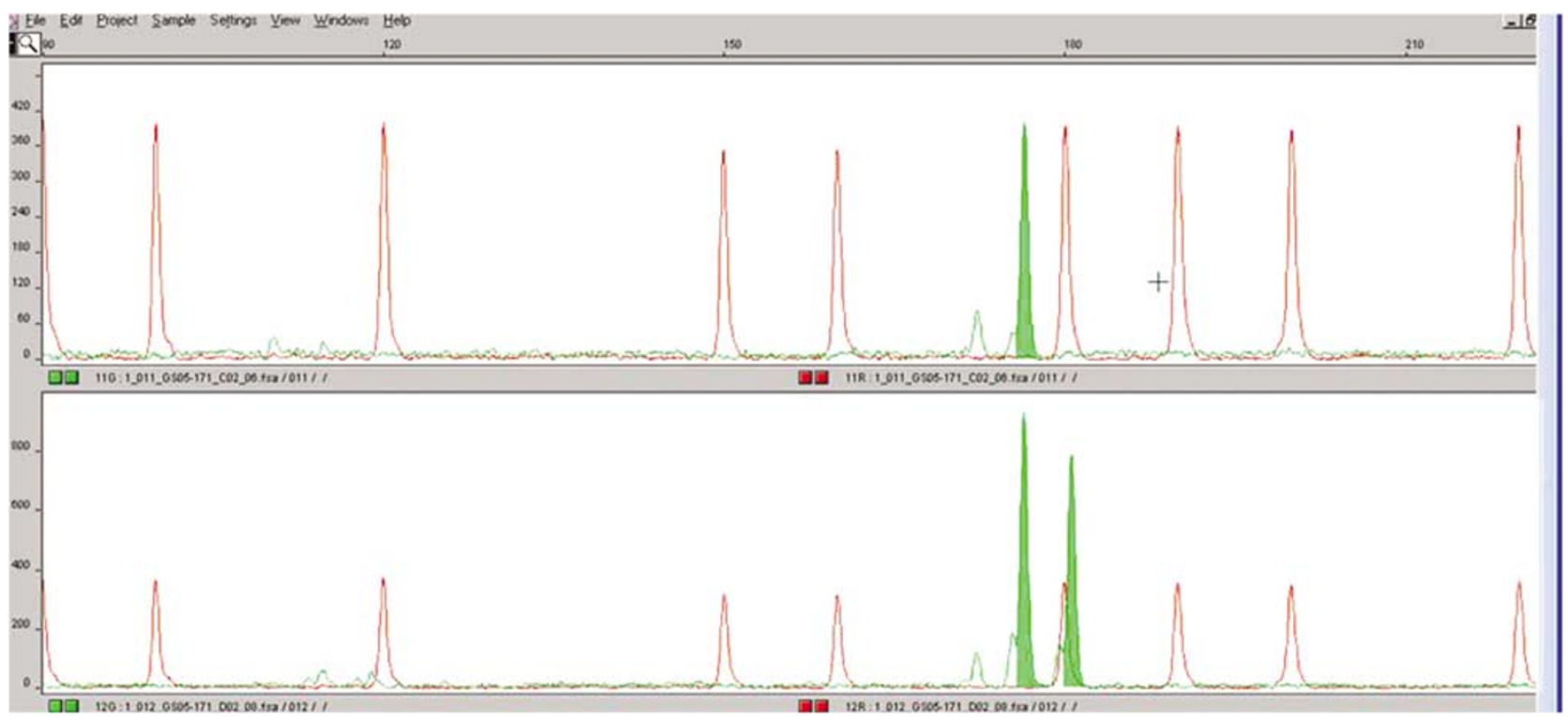

Figure 6 Allelic imbalance analysis of microdissected breast tissue. The bottom image represents non-neoplastic stromal tissue microdissected no larger than lesional sites. Note the presence of two polymorphic peaks of similar height. The ratio of peak heights is within a range determined by analyzing a large number of non-neoplastic tissue samples from patients with identical allele pairings (see Materials and methods). The top image clearly shows imbalance of one allele indicating mutation. The threshold for mutational change is two s.d. beyond the average for non-neoplastic samples (see Materials and methods). 
5q23:D5S592[L16423], 5q23:D5S615[L18737], 9p21:D9S251[L18726], 9p23:D9S254[L18050], 10q23:D10S520[L16357], 10q23:D10S1173[L30341], 17p13:D17S974[G07961] and 17p13D17S1289[G09615].

Microdissected tissue was PCR amplified with flanking oligonucleotides bearing fluorescent labels designed for GeneScan fragment analysis (Applied Biosystems). PCR products were separated by capillary electrophoresis (ABI 310, Applied Biosystems). In all cases, microdissected normal samples were run in parallel, serving as an internal negative control. To control for allelic dropout due to insufficient template, all microdissected normal tissue samples were taken to be no larger in size and to contain no more cells than the smallest microdissected lesional sample. All such normal internal controls were required to demonstrate allelic balance as defined below.

Fluorescent labeled oligonucleotide primers were employed for quantitative determination of allelic imbalance based on the peak height ratio of polymorphic microsatellite alleles. Postamplification products were electrophoresed and relative fluorescence determined for individual allele peak height (GeneScan ABI3100, Applied Biosystems, Foster City, CA, USA). The ratio of peaks was calculated by dividing the value for the shorter sized allele by that of the longer sized allele (Figure 4). Thresholds for significant allelic imbalance were determined beforehand in extensive studies using normal (nonneoplastic) specimens representing each unique pairing of individual alleles for every marker used in the panel. Peak height ratios falling outside of two s.d. beyond the mean for each polymorphic allele pairing were assessed as showing significant allelic imbalance.

Normal microdissected tissue samples were first evaluated for informative status with respect to individual alleles. When a particular microsatellite marker in a normal tissue sample manifested only a single peak, the patient was designated as noninformative for that marker. For informative subjects with respect to a specific marker, alleles were assessed as being in balance when the ratio of the individual allele peaks fell within two s.d. of the average generated from a large series of nonneoplastic microdissected tissue samples for subjects with the same pairing of specific polymorphic alleles.

\section{Results}

Detailed allelic imbalance information was obtained from each microdissected tissue target producing a detailed fingerprint of mutational damage in each case. The overall results are summarized in (Tables 2-4).

A total of 10 normal lobules had no $\mathrm{LOH}$ from normal tissues or from tissues with carcinoma on the same slide. Two out of two cases of columnar
Table 2 Frequency of LOH in columnar cell lesion types

\begin{tabular}{lcccc}
\hline Locus & CCH & ACCH & DCIS & IC \\
\hline 17q12 & & 4 & 3 & 6 \\
1p36.12 & & 1 & 4 & 3 \\
9q22.1 & 1 & 4 & 4 & 4 \\
9p23 & 2 & 1 & 1 \\
5q23.3 & & 2 & 1 & 1 \\
17p13.1 & & 2 & 1 & 1 \\
10q23.31 & 1 & & 1 & 1 \\
3p25.3 & & 2 & & 2 \\
3p26.3 & & & & 1 \\
22q22 & & & 1 \\
5q23.3 & & & & 1 \\
1p34.1 & & & &
\end{tabular}

$\mathrm{CCH}$, columnar cell hyperplasia; ACCH, atypical columnar cell hyperplasia; DCIS, ductal carcinoma in situ; IC, invasive carcinoma.

Table 3 Ranges of fractional mutation percentages of columnar cell lesions

\begin{tabular}{ccccccc}
\hline & Normal & CCC & CCH & ACCH & DCIS & IC \\
\hline FMP & 0 & 0 & $0-15 \%$ & $0-20 \%$ & $0-36 \%$ & $0-40 \%$
\end{tabular}

FMP, fractional mutation percentage; $\mathrm{CCH}$, columnar cell hyperplasia; ACCH, atypical columnar cell hyperplasia; DCIS, ductal carcinoma in situ; IC, invasive carcinoma.

Table 4 Percentage of columnar lesion diagnostic categories with $\mathrm{LOH}$

\begin{tabular}{ccccc}
\hline CCC & CCH & ACCH & DCIS & IDC \\
\hline $0 / 3$ & $2 / 3$ & $10 / 15$ & $10 / 10$ & $8 / 8$ \\
$0 \%$ & $66 \%$ & $66 \%$ & $100 \%$ & $100 \%$
\end{tabular}

CCH, columnar cell hyperplasia; ACCH, atypical columnar cell hyperplasia; DCIS, ductal carcinoma in situ; IC, invasive carcinoma.

cell change had no LOH. Two of the three hyperplastic columnar lesions cases had $\mathrm{LOH}$ at 9q22.1 and 10q23.31. Atypical hyperplasia of columnar cell type, DCIS and invasive carcinoma showed LOH in 10/11 cases. The maximal fractional mutation percentages increased progressively from simple columnar cell change (0\%), to columnar cell hyperplasia (15\%), atypical columnar cell hyperplasia $(20 \%)$, DCIS $(36 \%)$ and invasive carcinoma (40\%) (Table 3).

\section{Discussion}

Columnar cell lesions can be divided into two broad categories: columnar cell change and columnar cell hyperplasia. Each category has a subcategory of 'with atypia'. In the broadest sense, we consider the atypical categories to be viewed as atypical duct epithelial hyperplasia. A summary of histopathologic features ${ }^{17}$ and mutational changes are summarized in Table 4. 
Columnar cell lesions are discovered on mammograms because they are associated with calcifications of the calcium phosphate type. At Magee-Women's Hospital, columnar cell alterations rank fifth as the pathologic finding associated with mammographic calcifications behind fibrocystic change, fibroadenoma, DCIS and sclerosing adenosis.

Mutational analysis by $\mathrm{LOH}$ in this study validates the morphologic spectrum impression of a kinship within the family of columnar alterations. A low level of allelic imbalance was demonstrable in columnar cell lesions using the microdissection approach. A gradient of progressive mutational change could be delineated in each case manifesting allelic loss damage. Allelic loss damage appeared to preferentially target loci at 9q, 10q, 17p and 17q. Mutational change in hyperplastic and atypical lesions are commonly seen in DCIS and invasive carcinoma. The LOH patterns seen in atypical columnar cell lesions are also demonstrated in DCIS and invasive carcinoma, consistent with molecular neoplastic progression. The findings are consonant with the hypothesis that atypical columnar cell lesions are morphologic precursors to invasive carcinoma.

Biomarker studies of estrogen and progesterone (ER/PR) receptors,,${ }^{8,19}$ - bcl-2, ${ }^{19}$ CyclinD1 ${ }^{22}$ on columnar cell alterations have demonstrated alterations compared to normal lobules. Columnar cell lesions routinely display strong and diffuse ER/PR compared to the focal and variable immunostaining of surrounding lobules. Upregulation of ER suggests the possibility that columnar alterations have escaped normal ER regulation and that it may represent one avenue to an ER-dependent pathway to carcinoma. Accelerated growth fractions of proliferative and atypical columnar alterations manifested by increased Ki-67 indices, cyclin D1 expression and antiapoptosis signaling with bcl-2 are supportive of this hypothesis.

Oyama $^{8}$ noted the close geometric proximity of cystic lobules of columnar type, atypical proliferations and DCIS and concluded that the atypical cystic lobules were an early phase in the pathway to DCIS.

There are several studies in the literature that address molecular evolution of preneoplastic breast proliferations, but they do not specifically address the columnar line of proliferation.

O'Connell et al ${ }^{23}$ found $\mathrm{LOH}$ in $50 \%$ of duct epithelial hyperplasia with and without atypia, and in $80 \%$ of DCIS. Lakhani et $a l^{24}$ observed an $\mathrm{LOH}$ rate of $55 \%$ at $17 p$ (D17S796) and 16q (D16S413). Chuaqui et $a l^{25}$ using $11 \mathrm{q} 13$ found only $9 \%$ of cases had LOH in atypical hyperplasia and $27 \%$ in DCIS. None of the low-grade DCIS cases in his study showed LOH at the 11q13 locus, while high-grade DCIS had LOH in $35 \%$ of cases. We did not examine the 11q13 locus in this study.

O'Connell et $a{ }^{26}$ in a study of 399 premalignant cases found that $37 \%$ of usual hyperplasia and $42 \%$ of atypical hyperplasias show $\mathrm{LOH}$ at one locus, while finding $70 \%$ of noncomedo and $79 \%$ of comedo DCIS showing at least one loss. Identical percentages of preneoplastic cases shared LOH with synchronous cancers.

Papillary tumors of the breast also show $\mathrm{LOH}$ in benign, atypical and in situ carcinomas. ${ }^{27}$ Studies by Amari et $a l^{28}$ Washington et $a l^{29}$ and Maitra et $a l^{30}$ showed frequent losses at $3 p$ (multiple discontinuous regions), and 8p, 16q, 17q. Washington also discovered $\mathrm{LOH}$ of at least one type with fibrocystic change components, including apocrine metaplasia adjacent to tumors. In our study, we examined only normal appearing lobules adjacent to preneoplastic change and tumors, but did not find $\mathrm{LOH}$ at any of the 20 sites.

Kaneko ${ }^{31}$ demonstrated increasing frequencies of $\mathrm{LOH}$ in usual ductal hyperplasia from those without atypia through $\mathrm{ADH}$.

Moinfar et $a l^{15}$ studied 13 cases of 'flat atypia', referred to as 'clinging carcinoma', finding that $70 \%$ showed LOH at one or more of the loci and that these mutations were the same in DCIS and invasive carcinoma.

The $70 \% \mathrm{LOH}$ rate that Moinfar found in the lesions of flat atypia is comparable to our findings in atypical epithelial hyperplasia.

To summarize, columnar cell lesions represent a spectrum from simple 'change' of terminal duct lobular epithelium to invasive carcinoma. Select atypical groups in this morphologic spectrum, observed by many for a long time, clearly display molecular abnormalities that progressively accumulate into those lesions that we recognize as DCIS. The 'early lesions' referred to by Oyama represent a particularly challenging focus. They are without molecular abnormalities and may represent nonobligate precursors to neoplasia. Systematic prospective follow-up of patients with columnar cell lesions would contribute immensely to our understanding of the natural history of this entity.

\section{References}

1 Page DL, Anderson TJ. Diagnostic Histopathology of the Breast. Churchill Livingston: Edinburgh, Scotland, 1987.

2 Bosner G, Dossett JA, Jull W. Human and Experimental Breast Cancer. Pittman Medical: New York, 1961, pp 336-347.

3 Trojani M. Atlas en Couleurs d'Histopathologie Mammaire. Maloine: Paris, 1988.

4 Foote FWJ, Stewart FW. Comparative studies of cancerous vs. noncancerous breasts. Basic morphologic characteristics. Ann Surg 1916;12:6-53.

5 Azzopardi JG. Problems in Breast Pathology. WB Saunders: Philadelphia, 1979, pp 29-37.

6 Gallager HS. Sources of uncertainty in interpretation of breast biopsies. Breast 1976;2:12-15.

7 Wellings SR, Jensen HM, Marcum RG. An atlas of subgross pathology of the human breast with special reference to possible precancerous lesions. J Natl Cancer Inst 1975;55:231-273. 
8 Oyama T, Iijim K, Takei H, et al. Atypical cystic lobule of the breast: an early stage of low grade ductal carcinoma in-situ. Breast Cancer 2000;7:326-331.

9 Tsuchiya S. Atypical ductal hyperplasia, atypical lobular hyperplasia, and interpretation of a new borderline lesion. Jpn J Cancer Clin 1998;44:355-548.

10 Rosen PP. Rosen's Breast Pathology. Lippincott Williams \& Wilkins: Philadelphia, 2001, pp 215-225.

11 Rosen PP. Columnar cell hyperplasia is associated with lobular carcinoma in situ and tubular carcinoma. Am J Surg Pathol 1999;23:1561.

12 Goldstein NS, O’Malley BA. Cancerization of small ectatic ducts of the breast by ductal carcinoma in situ cells with apocrine snouts: a lesion associated with tubular carcinoma. Am J Clin Pathol 1997;107: 561-566.

13 Page DL, Jensen RA. Hypersecretory hyperplasia with atypia in breast biopsies. What is the proper level of clinical concern? Pathol Case Rev 1996;1: 36-40.

14 Fraser JL, Raza S, Chorny K, et al. Columnar alteration with prominent apical snouts and secretions: a spectrum of changes frequently present in breast biopsies performed for microcalcifications. Am J Surg Pathol 1998;22:1521-1527.

15 Moinfar F, Man YG, Bratathauert GL, et al. Genetic abnormalities in mammary ductal intraepithelial neoplasia-flat type ('clinging ductal carcinoma in situ'): a simulator of normal mammary epithelium. Cancer 2000;88:2072-2081.

16 McLaren BK, Gobbi H, Schuyler PA, et al. Immunohistochemical expression of estrogen receptor in enlarged lobular units with columnar alteration in benign breast biopsies: a nested case-control study. Am J Surg Pathol 2005;29:105-108.

17 Schnitt SJ, Vincent-Salomon A. Columnar cell lesions of the breast. Adv Anat Pathol 2003;10:113-124.

18 Schnitt SJ. The diagnosis and management of preinvasive breast disease: flat epithelial atypia-classification, pathologic features and clinical significance. Breast Cancer Res 2003;5:263-268.

19 Fraser JL, Raza S, Chorny K, et al. Immunophenotype of columnar alteration with prominent apical snouts and secretions (CAPSS). Lab Invest 2000;80:21A.
20 Allred DC, Mohsin SK, Fuqua SA. Histological and biologic evolution of human premalignant breast disease. Endocr Relat Cancer 2001;8:47-61.

21 Dabbs DJ, Peng Y, Carter G, et al. Molecular alterations in columnar cell lesions of the breast. Mod Pathol 2004;17:27A.

22 Oyama T, Maluf H, Koerner F. Atypical cystic lobules: an early stage in the formation of low-grade ductal carcinoma in situ. Virchows Arch 1999;435:13-21.

23 O’Connell P, Pekkel V, Fuqua S, et al. Molecular genetic studies of early breast cancer evolution (Review). Breast Cancer Res Treat 1994;32:5-12.

24 Lakhani SR, Collins N, Stratton MR, et al. Atypical ductal hyperplasia of the breast: clonal proliferation with loss of heterozygosity on chromosomes $16 \mathrm{q}$ and 17p. J Clin Pathol 1995;48:611-615.

25 Chuaqui RF, Zhuang Z, Emmert-Buck MR, et al. Analysis of loss of heterozygosity on chromosome $11 q 13$ in atypical ductal hyperplasia and in situ carcinoma of the breast. Am J Pathol 1997;150:297-303.

26 O’Connell P, Pekkel V, Fuqua SA, et al. Analysis of loss of heterozygosity in 399 premalignant breast lesions at 15 genetic loci. J Natl Cancer Inst 1998;90:697-703.

27 Lininger RA, Park WS, Man YG, et al. LOH at 16p13 is a novel chromosomal alteration detected in benign and malignant microdissected papillary neoplasms of the breast. Hum Pathol 1998;29:1113-1118.

28 Amari M, Suzuki A, Moriya T, et al. LOH analyses of premalignant and malignant lesions of human breast: frequent $\mathrm{LOH}$ in $8 \mathrm{p}, 16 \mathrm{q}$, and $17 \mathrm{q}$ in atypical ductal hyperplasia. Oncol Rep 1999;6:1277-1280.

29 Washington C, Dalbegue F, Abreo F, et al. Loss of heterozygosity in fibrocystic change of the breast: genetic relationship between benign proliferative lesions and associated carcinomas. Am J Pathol 2000;157:323-329.

30 Maitra A, Wistuba II, Washington C, et al. Highresolution chromosome $3 p$ allelotyping of breast carcinomas and precursor lesions demonstrates frequent loss of heterozygosity and a discontinuous pattern of allele loss. Am J Pathol 2001;159:119-130.

31 Kaneko M, Arihiro K, Takeshima Y, et al. Loss of heterozygosity and microsatellite instability in epithelial hyperplasia of the breast. J Exp Ther Oncol 2002; 2:9-18. 